\title{
Efficacy of noninvasive CPAP in COPD with acute respiratory failure
}

\author{
P. Goldberg+*, H. Reissmann**, F. Maltais**, M. Ranieri**, S.B. Gottfried**\#
}

\begin{abstract}
Efficacy of noninvasive CPAP in COPD with acute respiratory failure. P. Goldberg, $H$. Reissmann, F. Maltais, M. Ranieri, S.B. Gottfried. (OERS Journals Ltd 1995.

ABSTRACT: Dynamic hyperinflation and the development of intrinsic positive end-expiratory pressure (PEEPi) are commonly observed in patients with severe chronic obstructive pulmonary disease (COPD) in acute respiratory failure. Previous studies have shown that externally applied PEEP reduces PEEPi and its adverse effects in mechanically-ventilated COPD patients. The purpose of this study was to determine the effects of graded amounts of continuous positive airway pressure (CPAP) on the degree of inspiratory effort, pattern of breathing, gas exchange, and level of dyspnoea in a group of spontaneously breathing, nonintubated COPD patients in acute hypercapnic respiratory failure.

Ten COPD patients admitted to the intensive care unit in acute hypercapnic respiratory failure were studied. Inspiratory effort was measured by the tidal excursions of oesophageal $\left(P_{\text {oes }}\right)$ and transdiaphragmatic $\left(P_{\mathrm{di}}\right)$ pressure. Inspiratory effort and both the pressure-time product for the diaphragm $\left(\int P_{\mathrm{di}} \cdot \mathrm{dt}\right)$ and for the inspiratory muscles $\left(\int_{P_{0}} \cdot d t\right)$ were measured during the application of $5,7.5$, and 10 $\mathrm{cmH}_{2} \mathrm{O}$ of CPAP. Dyspnoea, gas exchange and pattern of breathing were also assessed.

Inspiratory effort and the pressure-time product both for the diaphragm and the inspiratory muscles fell significantly with CPAP in a dose-dependent fashion. Both the pattern of breathing and level of dyspnoea improved with CPAP. End-expiratory lung volume remained stable at the lower levels of CPAP, with only modest increases at the higher levels. Arterial oxygen tension $\left(\mathrm{Pa}_{\mathrm{a}} \mathrm{O}_{2}\right)$ and arterial carbon dioxide tension $\left(\mathrm{Pa}_{\mathrm{a}} \mathrm{CO}_{2}\right)$ either improved or remained stable with CPAP.

We conclude that the noninvasive application of CPAP to spontaneously breathing patients with severe COPD in acute respiratory failure decreases inspiratory effort and dyspnoea whilst improving breathing pattern. It is conceivable that the early institution of CPAP in this setting may obviate the need for intubation and conventional mechanical ventilation.
\end{abstract}

Eur Respir J., 1995, 8, 1894-1900.

+Montreal Chest Hospital Centre, *Royal Victoria Hospital (Critical Care Division), \#Montreal General Hospital and **MeakinsChristie Laboratories, McGill University, Montreal, Québec, Canada.

Correspondence: P. Goldberg

Critical Care Division

Royal Victoria Hospital

687 Pine Ave West

Montreal, QC

H3A 1 A1

Canada

Keywords: Chronic obstructive airways disease continuous positive airway pressure

hypercapnic respiratory failure

Received: November 301994

Accepted after revision August 41995

Presented in part at the Annual Meeting of the American College of Chest Physicians, October 22-26, 1990 (Toronto, Ontario, Canada).
Classically, the increase in the work of breathing accompanying an acute exacerbation of chronic obstructive pulmonary disease (COPD) has been attributed primarily to an increased resistive load. Accordingly, therapeutic approaches have focused on its pharmacological reduction. Recently, however, it has become apparent that individuals with COPD, both when stable and especially during an acute decompensation, exhibit dynamic hyperinflation which has profound consequences on the energetics of breathing. Indeed, dynamic hyperinflation, which is reflected by the intrinsic positive end-expiratory pressure (PEEPi), imposes an added inspiratory threshold load whilst decreasing the effectiveness of the inspiratory muscles as pressure generators. Several investigators $[1,2]$ have shown that positive end-expiratory pressure applied externally can counterbalance PEEPi without causing further hyperinflation.

We undertook this study, therefore, to determine whether the application of continuous positive airway pressure
(CPAP) to spontaneously breathing patients in hypercapnic respiratory failure, due to an acute exacerbation of COPD, could decrease inspiratory effort and dyspnoea and improve breathing pattern.

\section{Methods}

Ten severely dyspnoeic patients admitted to the intensive care unit (ICU) of the Montreal Chest Hospital Centre in worsening hypercapnic respiratory failure were studied. Of these patients, six were studied during their first day of admission to the ICU. One patient (No. 8) was studied several days after admission, following extubation and subsequent worsening respiratory status, as documented by his arterial blood gases (table 1). The other three patients were initially managed pharmacologically by their treating physicians. When, in the opinion of those physicians, therapy had proved inadequate, these 
Table 1. - Patient characteristics

\begin{tabular}{|c|c|c|c|c|c|c|c|c|c|}
\hline \multirow{2}{*}{$\begin{array}{r}\mathrm{Pt} \\
\text { No. }\end{array}$} & \multirow{2}{*}{$\begin{array}{l}\text { Age } \\
\text { yrs }\end{array}$} & \multirow[t]{2}{*}{ Sex } & \multirow{2}{*}{$\begin{array}{c}\mathrm{FEV}_{1 / \mathrm{FVC}} \\
\mathrm{L}\end{array}$} & \multicolumn{2}{|c|}{$P \mathrm{a}, \mathrm{O}_{2}$} & \multicolumn{2}{|c|}{$\mathrm{Pa}_{\mathrm{a}, \mathrm{CO}_{2}}$} & \multirow[t]{2}{*}{$\mathrm{pH}$} & \multirow[t]{2}{*}{$F \mathrm{I}, \mathrm{O}_{2}$} \\
\hline & & & & $\mathrm{kPa}$ & $\mathrm{mmHg}$ & $\mathrm{kPa}$ & $\mathrm{mmHg}$ & & \\
\hline 1 & 58 & M & $0.45 / 1.65$ & 6.3 & 47 & 9.9 & 74 & 7.15 & 0.21 \\
\hline 2 & 61 & $\mathrm{~F}$ & $0.52 / 1.49$ & 7.2 & 54 & 10.1 & 76 & 7.26 & 0.40 \\
\hline 3 & 62 & M & $0.44 / 1.67$ & 11.6 & 87 & 10.8 & 81 & 7.32 & 0.28 \\
\hline 4 & 28 & M & $1.16 / 3.10$ & 11.6 & 87 & 6.4 & 48 & 7.38 & 0.35 \\
\hline 5 & 77 & M & $0.58 / 1.86$ & 8.8 & 66 & 10.4 & 78 & 7.39 & 0.30 \\
\hline 6 & 70 & $\mathrm{~F}$ & $0.70 / 1.36$ & 10.1 & 76 & 7.9 & 59 & 7.29 & 0.50 \\
\hline 7 & 61 & $\mathrm{~F}$ & $1.16 / 2.37$ & 8.3 & 62 & 9.1 & 68 & 7.25 & 0.28 \\
\hline 8 & 65 & M & $1.08 / 2.38$ & 6.8 & 51 & 10.9 & 82 & 7.35 & 0.35 \\
\hline 9 & 64 & M & $0.50 / 1.95$ & 11.3 & 85 & 7.3 & 55 & 7.40 & 0.28 \\
\hline 10 & 68 & M & $0.38 / 1.20$ & 8.4 & 63 & 7.2 & 54 & 7.44 & 0.30 \\
\hline
\end{tabular}

FEV1/FVC were obtained when stable prior to the present hospitalization. Pt: patient; M: male; F: female; FEV1: forced expiratory volume in one second; FVC: forced vital capacity; $P \mathrm{a}, \mathrm{O}_{2}$ : arterial oxygen tension; $\mathrm{Pa}_{\mathrm{a}, \mathrm{CO}_{2}}$ : arterial carbon dioxide tension; $F \mathrm{I}, \mathrm{O}_{2}$ : inspiratory oxygen fraction.

patients were entered into the study. Their arterial blood gas values listed in table 1 represent the period just prior to enrolment in the study. The diagnosis of chronic airflow obstruction was confirmed by history and physical examination, as well as by previous pulmonary function tests. In all but one patient who suffered from cystic fibrosis (No. 4) this condition was due to tobacco abuse. The precipitating cause of the acute decompensation was acute bronchitis in all patients. Pertinent clinical information is provided in table 1 . None of the patients had evidence of myocardial ischaemia or failure, haemodynamically compromising dysrhythmias, or altered mental status. Medical management was continued as prescribed by the primary physicians. The investigative protocol was approved by the Institutional Ethics Committee, and written informed consent was obtained from the patient or family in all cases.

All patients, none of whom was intubated at the time of this study, were studied whilst breathing spontaneously in the semirecumbent position. They breathed either through a mouthpiece with a noseclip in place (eight patients) or a face-mask with inflatable rim (two patients), the choice being based on goodness of fit, absence of leaks, and patient comfort. The mouthpiece or mask was connected to a continuous high flow system (approximately $100 \mathrm{~L} \cdot \mathrm{min}^{-1}$ ) (Downs Flow Generator No. 9250, Vital Signs Inc., Totowa, NJ, USA). The inspired oxygen fraction $\left(F \mathrm{I}, \mathrm{O}_{2}\right)$ was initially chosen to achieve an arterial oxygen tension $\left(\mathrm{Pa}_{\mathrm{a}} \mathrm{O}_{2}\right)$ of $8.0 \mathrm{kPa}(>60 \mathrm{mmHg})$ and remained constant throughout the remainder of the study.

Flow $\left(V^{\prime}\right)$ was measured with a heated Fleisch No. 2 pneumotachograph (three patients) or with a variable orifice pneumotachograph (Cat. No. 279331, Hamilton Medical, Inc., Reno, NV, USA) (seven patients) connected to a differential pressure transducer (MP-45, $\pm 2 \mathrm{cmH}_{2} \mathrm{O}$, Validyne Corp., Northridge, CA, USA). Pressure at the airway opening $(P \mathrm{ao})$ was recorded proximal to the pneumotachograph using a differential pressure transducer (Validyne MP-45, $\pm 100 \mathrm{cmH}_{2} \mathrm{O}$ ). Oesophageal pressure ( $\left.P_{\text {oes }}\right)$ was measured using balloon-tipped catheter systems. Three patients were studied with a $10 \mathrm{~cm}$ long balloon integrated into a gastric tube [3] (Cat. No. 85843, National Catheter Co., Argyle, NY, USA), the others with a latex balloon of the same length mounted on a polyethylene catheter (length $100 \mathrm{~cm}$; internal diameter $1.7 \mathrm{~mm}$ ) [4]. In five patients [5], gastric pressure $(P \mathrm{ga})$ was also measured using a second balloon-catheter system. The balloons were filled with $1 \mathrm{~mL}$ of air and connected to separate differential pressure transducers (Validyne MP-45, $\pm 100 \mathrm{cmH}_{2} \mathrm{O}$ ). The oesophageal balloon was properly positioned using the "occlusion test" as described previously [4]. Where applicable, transdiaphragmatic pressure $(P \mathrm{di})$ was determined by subtracting $P$ oes from $P$ ga. A DC-coupled respiratory inductance plethysmograph (RIP) (Respitrace, Ambulatory Monitoring, Ardsley, NY, USA) was used to monitor endexpiratory lung volume. The bands were placed around the rib cage at the level of the nipples and around the abdomen at the level of the umbilicus. Care was taken to avoid the overlap of the two bands.

All of the above variables were recorded on an eight channel strip-chart recorder (7718A, Hewlett-Packard Fullerton, CA, USA) together with an additional volume trace obtained by electrical integration of the flow signal (Hewlett-Packard 8815A). The signals were also simultaneously filtered, digitized (DT 2801A, Data Translation, Marlboro, MA, USA) and stored on a portable computer (SuperSport 286, Zenith Data Systems, St. Joseph, MI, USA) for later analysis.

\section{Procedure and analysis}

After a period of accommodation to the experimental apparatus, the patients breathed spontaneously for approximately $10 \mathrm{~min}$ at atmospheric pressure (Control). CPAP of $5 \mathrm{cmH}_{2} \mathrm{O}$ was then applied to the circuit by attaching a spring-loaded threshold valve (Vital Signs, East Rutherford, NJ, USA) to the respiratory circuit for approximately $10 \mathrm{~min}$. This was followed by another 10 min control period of breathing at atmospheric pressure. Similar control and CPAP trials were repeated with CPAP of $7.5 \mathrm{cmH}_{2} \mathrm{O}$ (eight patients) and $10 \mathrm{cmH}_{2} \mathrm{O}$ (three patients), the lesser number of patients at the higher levels due to patient discomfort and/or the presence of a leak around the mask or mouthpiece. At the end of each control and CPAP period, arterial blood 


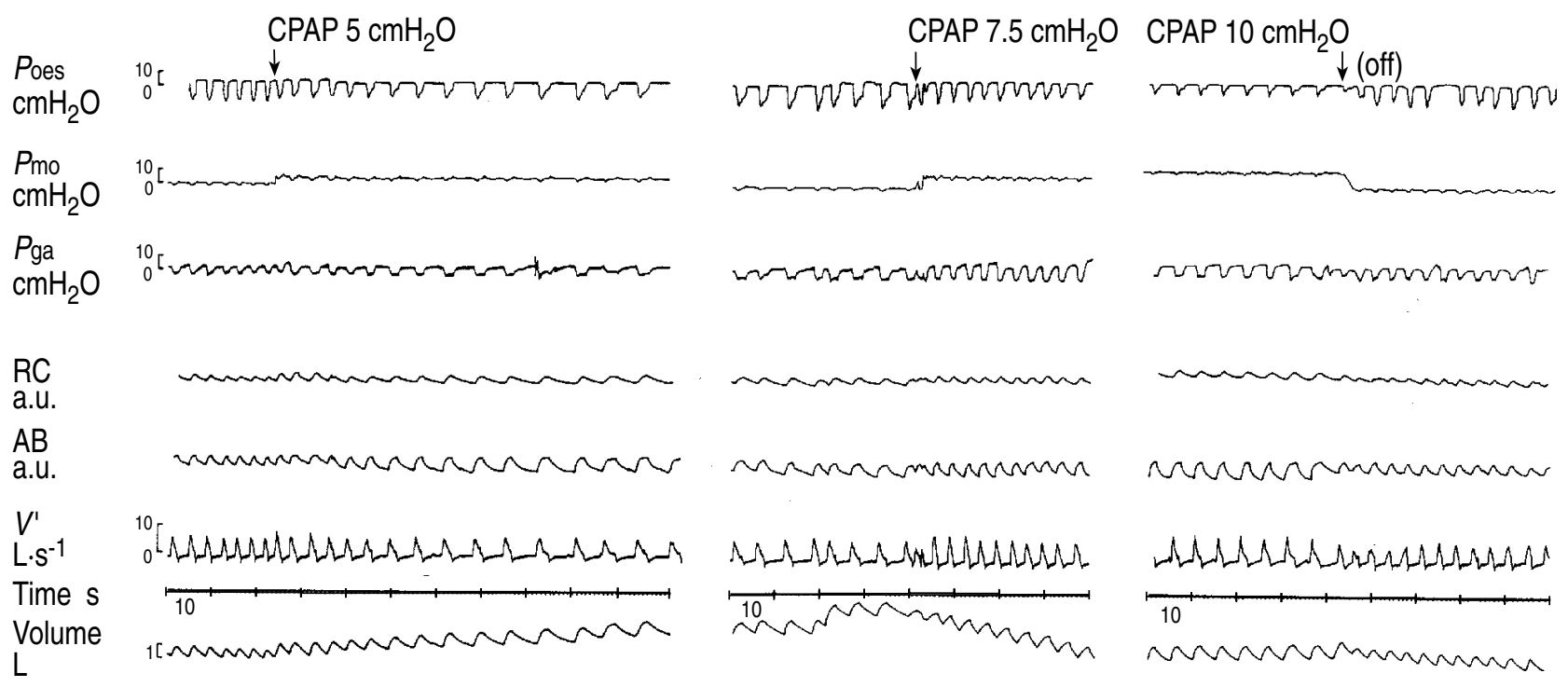

Fig. 1. - Effects of continuous positive airway pressure (CPAP) in a representative patient. From top to bottom, tracings represent oesophageal pressure $\left(P_{\mathrm{oes}}\right)$, mouth pressure $\left(P_{\mathrm{mo}}\right)$, and gastric pressure $(P \mathrm{ga})$, volume displacement of the rib cage $(\mathrm{RC})$ and abdomen $(\mathrm{AB})$, and flow $\left(V^{\prime}\right)$ and tidal volume. a.u: arbitrary unit. See text for interpretation.

samples were drawn for determination of $\mathrm{Pa}_{\mathrm{a}} \mathrm{O}_{2}$, arterial carbon dioxide tension $\left(\mathrm{Pa}_{\mathrm{a}} \mathrm{CO}_{2}\right)$, and $\mathrm{pH}$. At the same time, patients were asked to indicate any change in their level of dyspnoea between control and CPAP conditions using a bidirectional ordinal scale $(0=$ no change; $-1 /+1=$ very slight worsening/improvement; $-2 /+2=$ slight worsening/improvement; $-3 /+3=$ moderate worsening/improvement; $-4 /+4$ marked worsening/improvement; $-5 /+5=$ very marked worsening/improvement) [5]. Heart rate, blood pressure, and oxygen saturation were monitored throughout the study.

Approximately 10-15 consecutive breaths were analysed for each experimental condition once a stable breathing pattern was observed. Tidal volume $(V \mathrm{~T})$, digitally integrated from the flow signal, and respiratory rate were both determined. The duration of inspiration $(t \mathrm{I})$, expiration $(t \mathrm{E})$, and total breathing cycle ( $t$ tot) were also calculated. As an indication of inspiratory effort, tidal excursions of $P$ oes and $P$ di were determined. The area under the pressure-time relationship, i.e. the pressuretime product for both the inspiratory muscles $\left(\int P_{\text {oes }} \cdot \mathrm{dt}\right)$ and diaphragm $\left(\int P \mathrm{di} \cdot \mathrm{dt}\right)$ were determined and expressed per minute and per litre of minute ventilation [6].
Results are expressed as mean value \pm standard error. As measurements made in the control periods both preceding and following the application of CPAP were no different their results were averaged

All comparisons between CPAP and the corresponding averaged control period were made using Student's $\mathrm{t}$-test for paired data. Statistical significance was defined as a p-value less than 0.05 .

\section{Results}

A representative experimental record of one patient at baseline and at CPAP of 5, 7.5 and $10 \mathrm{cmH}_{2} \mathrm{O}$ is presented in figure 1. As can be appreciated, each successive level of CPAP is associated with a progressive decrease in Poes swings in an apparent dose-dependent fashion, whilst tidal volume appears to remain constant or increases slightly. Importantly, end-expiratory lung volume appears to remain constant at all levels of applied CPAP, as suggested by the absence of any appreciable shift in the end-expiratory positions of the rib cage, abdominal, and $P$ oes signals.

Table 2. - Ventilatory parameters before and during CPAP

\begin{tabular}{|c|c|c|c|c|c|c|c|c|c|c|}
\hline \multirow[b]{2}{*}{ Control } & \multicolumn{2}{|c|}{$\begin{array}{c}V^{\prime} \mathrm{E} \\
\mathrm{L} \cdot \mathrm{min}^{-1}\end{array}$} & \multicolumn{2}{|c|}{$\begin{array}{l}V \mathrm{~T} \\
\mathrm{~mL} \\
\end{array}$} & \multicolumn{2}{|c|}{$\begin{array}{c}\mathrm{R} f \\
\text { breaths } \cdot \mathrm{min}^{-1}\end{array}$} & \multicolumn{2}{|c|}{$\begin{array}{c}t \mathrm{t} / t \text { tot } \\
\%\end{array}$} & $\begin{array}{c}V \mathrm{~T} / t \mathrm{I} \\
\mathrm{mL} \cdot \mathrm{s}^{-1}\end{array}$ & $\begin{array}{l}V \mathrm{~T} / t \mathrm{E} \\
\mathrm{mL} \cdot \mathrm{s}^{-1}\end{array}$ \\
\hline & 8.35 & (0.69) & 373 & (32) & 23.4 & (2.3) & 30.7 & (1.39) & $448 \quad(34)$ & 195 (17) \\
\hline $\begin{array}{l}\text { CPAP } 5 \mathrm{cmH}_{2} \mathrm{O} \\
(\mathrm{n}=10)\end{array}$ & 8.85 & $(0.94)$ & 443 & $(36)^{* *}$ & 21.1 & $(2.7)^{* *}$ & 29.6 & (1.16) & $500 \quad(53)$ & 211 (23) \\
\hline Control & 9.00 & (1.01) & 424 & (39) & 22.3 & (3.3) & 30.2 & (1.43) & 494 (49) & 217 (27) \\
\hline $\begin{array}{l}\text { CPAP } 7.5 \mathrm{cmH}_{2} \mathrm{O} \\
(\mathrm{n}=8)\end{array}$ & 9.67 & $(0.75)$ & 463 & (30) & 21.8 & (2.7) & 31.2 & $(1.06)$ & 520 & 234 (18) \\
\hline Control & 7.13 & $(0.97)$ & 396 & (81) & 20.7 & (7.3) & 28.5 & (1.98) & $412 \quad(50)$ & $165(25)$ \\
\hline $\begin{array}{l}\text { CPAP } 10 \quad \mathrm{cmH}_{2} \mathrm{O} \\
(\mathrm{n}=3)\end{array}$ & 8.05 & $(2.24)$ & 474 & $(99) *$ & 18.9 & $(8.7)^{*}$ & 29.1 & $(4.55)$ & $456 \quad(96)$ & 193 (59) \\
\hline
\end{tabular}

Values are presented as mean, and SEM in parenthesis. CPAP: continuous positive airway pressure; $V^{\prime} \mathrm{E}$ : minute ventilation; $V \mathrm{~T}$ : tidal volume; Rf: respiratory frequency; $t \mathrm{I}$ : inspiratory time; $t \mathrm{E}$ : expiratory time; $t \mathrm{I} / t$ tot: duty cycle; $V \mathrm{~T} / t \mathrm{I}$ : mean inspiratory flow rate; $V \mathrm{~T} / t \mathrm{E}$ : mean expiratory flow rate. *: $\mathrm{p}<0.05 ; * *: \mathrm{p}<0.01$. CPAP $v s$ control. Control is the average of before and after. Numbers in brackets refers to the number of subjects. 
The ventilatory parameters at the different levels of applied CPAP in all subjects are outlined in table 2. CPAP improved the pattern of breathing at each level of applied pressure, in that respiratory rate tended to fall whilst tidal volume rose, maintaining minute ventilation constant. At 5 and at $10 \mathrm{cmH}_{2} \mathrm{O}$, the changes in both respiratory rate and tidal volume were highly significant, while at $7.5 \mathrm{cmH}_{2} \mathrm{O}$, the increase in tidal volume just failed to reach significance $(\mathrm{p}=0.059)$. CPAP produced little or no change in the other ventilatory parameters measured.

Inspiratory effort, as evidenced by the tidal excursions of both oesophageal and transdiaphragmatic pressure, both on and off CPAP, are represented graphically in figure 2 . The inspiratory exclusions of $P$ oes and $P$ di fell at all levels of CPAP, in what appears to be a dosedependent fashion. Although reduced by approximately $40 \%$, the change in $P$ di at $7.5 \mathrm{cmH}_{2} \mathrm{O}$ failed to reach statistical significance, probably because of the small number of subjects.

The mean pressure developed by the inspiratory muscles during the breathing cycle has been described as reflecting the energy cost of breathing more closely than the actual measurements of the external work performed $[7,8]$. Poes-dt and $\int P \mathrm{di} \cdot \mathrm{dt}$, calculated per minute and per litre of minute ventilation, are presented graphically in figures 3 and 4 , respectively. $\int P_{\mathrm{oes}} \cdot \mathrm{dt}$ fell significantly in a dose-dependent manner at all levels of applied CPAP,
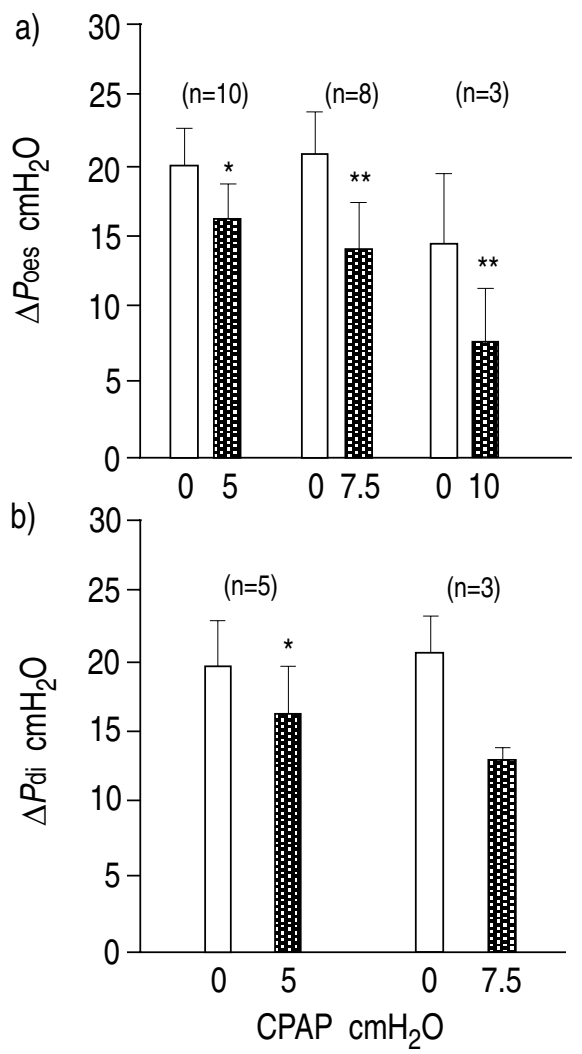

Fig. 2. - Average values ( \pm SEM) for the tidal swing in a) oesophageal pressure ( $\triangle P_{\text {oes }}$ ) before $(\square)$ and during ( tinuous positive airway pressure (CPAP) $5,7.5$ and $10 \mathrm{cmH}_{2} \mathrm{O}$ and in b) transdiaphragmatic pressure $(\triangle P \mathrm{di})$ before and during the application of CPAP 5 and $7.5 \mathrm{cmH}_{2} \mathrm{O}$. *: $\mathrm{p}<0.05$; **: $\mathrm{p}<0.01$ before $v s$ during CPAP. whilst $\int P \mathrm{di} \cdot \mathrm{dt}$ fell significantly at CPAP $5 \mathrm{cmH}_{2} \mathrm{O}$. Despite a decrease of approximately $45 \%$ in $P$ di.dt at CPAP 7.5 $\mathrm{cmH}_{2} \mathrm{O}$, both when calculated per minute and per litre,

a)

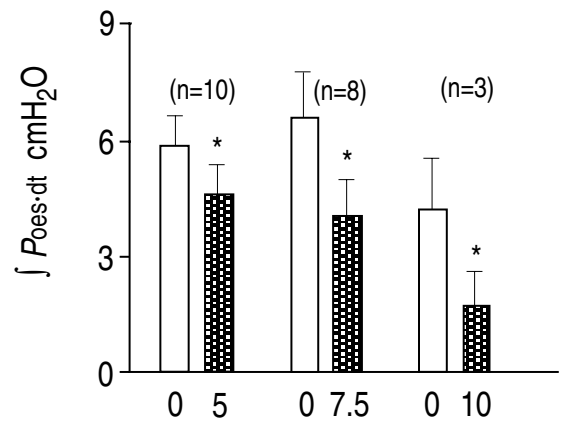

b)

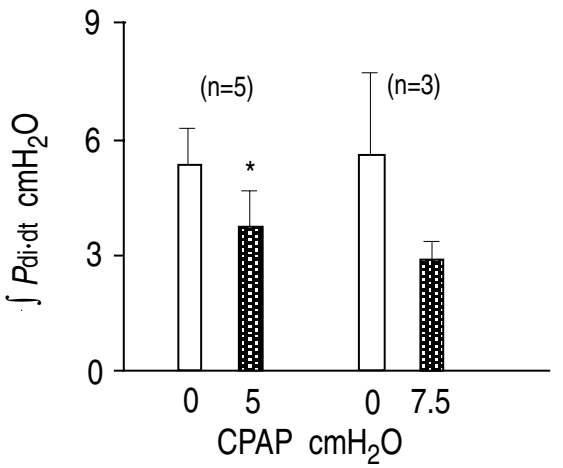

Fig. 3. - Average values ( \pm SEM) for the pressure-time product calculated for a period of $1 \mathrm{~min}$ of the a) inspiratory muscles $\left(J P_{\text {oes }}\right)$ before $(\square)$ and during ( pressure (CPAP) 5, 7.5 and $10 \mathrm{cmH}_{2} \mathrm{O}$ and of b) the diaphragm $\left(\int P_{\mathrm{di}} \cdot \mathrm{dt}\right)$ before and during the application of CPAP of 5 and $7.5 \mathrm{cmH}_{2} \mathrm{O}$. *: $\mathrm{p}<0.05$ before vs during CPAP.

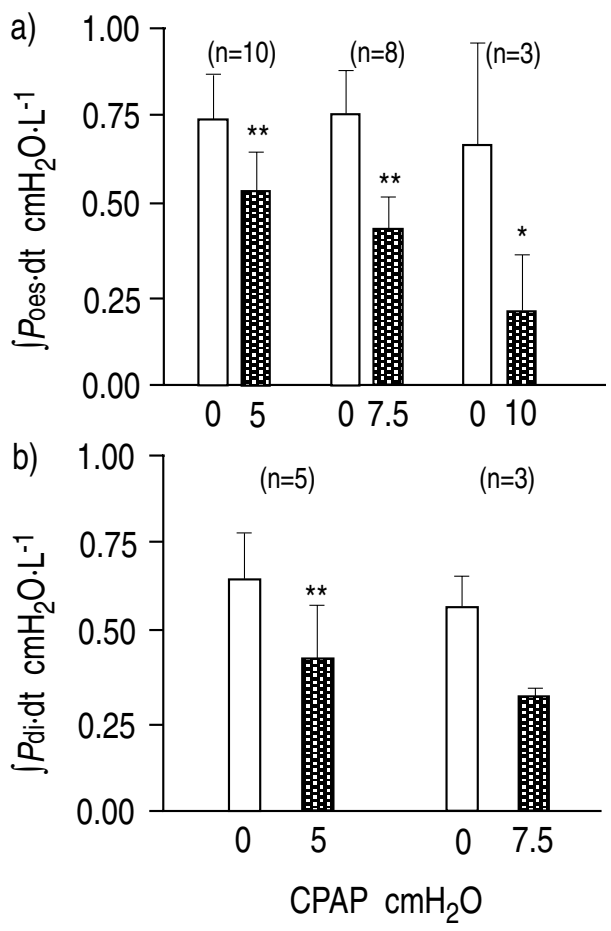

Fig. 4. - Average values ( \pm SEM) for the pressure-time product calculated per litre of minute ventilation of the a) inspiratory muscles $\left(\int P_{\mathrm{oes}} \cdot \mathrm{dt}\right.$ ) before $(\square)$ and during ( $\mathrm{B}$ ) continuous positive airway pressure (CPAP) 5, 7.5 and $10 \mathrm{cmH}_{2} \mathrm{O}$ and b) of the diaphragm $\left(\int P \mathrm{di} \cdot \mathrm{dt}\right)$ before and during the application of CPAP 5 and $7.5 \mathrm{cmH}_{2} \mathrm{O}$. *: $\mathrm{p}<0.05 ; * *: \mathrm{p}<0.01$ before $v s$ during CPAP. 
Table 3. - Arterial blood gases before and during CPAP

\begin{tabular}{|c|c|c|c|c|c|c|c|}
\hline \multirow[b]{3}{*}{ Control } & \multicolumn{3}{|c|}{$\mathrm{Pa}, \mathrm{O}_{2}$} & \multicolumn{2}{|c|}{$P \mathrm{a}, \mathrm{CO}_{2}$} & \multirow{2}{*}{\multicolumn{2}{|c|}{$\mathrm{pH}$}} \\
\hline & & $\mathrm{Pa}$ & $\mathrm{mmHg}$ & $\mathrm{kPa}$ & $\mathrm{mmHg}$ & & \\
\hline & 11.1 & (1.0) & $83 \quad(7.8)$ & $8.7 \quad(0.7)$ & $65 \quad(5.2)$ & 7.38 & $(0.03)$ \\
\hline $\begin{array}{l}\text { CPAP } 5 \mathrm{cmH}_{2} \mathrm{O} \\
(\mathrm{n}=9)\end{array}$ & 12.4 & $(0.8)$ & $93 \quad(6.3)$ & $8.3(0.6)$ & $62 \quad(4.2)$ & 7.40 & $(0.02)$ \\
\hline Control & 11.5 & (1.4) & 86 (10.7) & $8.1 \quad(0.8)$ & $61 \quad(5.9)$ & 7.39 & $(0.03)$ \\
\hline $\begin{array}{l}\text { CPAP } 7.5 \quad \mathrm{cmH}_{2} \mathrm{O} \\
(\mathrm{n}=7)\end{array}$ & 13.2 & $(1.5)^{*}$ & 99 (11.2)* & $7.9(0.7)$ & $59 \quad(4.9)$ & 7.41 & $(0.03)^{*}$ \\
\hline Control & 8.3 & $(1.2)$ & $62 \quad(8.7)$ & 9.3 & $70(10.2)$ & 7.33 & $(0.06)$ \\
\hline $\begin{array}{l}\text { CPAP } 10 \quad \mathrm{cmH}_{2} \mathrm{O} \\
(\mathrm{n}=3)\end{array}$ & 9.6 & $(0.8)$ & $72 \quad(5.7)$ & 8.5 (1.3) & $64 \quad(9.8)$ & 7.35 & $(0.07)$ \\
\hline
\end{tabular}

Values are presented as mean and SEM in parenthesis. *: p<0.05, CPAP vs control; control is average of before and after CPAP (paired t-test). Numbers in brackets refer to the number of subjects. For abbreviations see legends to tables 1 and 2 .

statistical significance was not achieved, probably due to the small number of patients studied under these conditions.

The effect of CPAP on arterial blood gases is shown in table 3. $\mathrm{Pa}, \mathrm{O}_{2}$ tended to improve at all levels of CPAP, whilst $P \mathrm{a}, \mathrm{CO}_{2}$ tended to remain constant or fall slightly. Similarly, arterial $\mathrm{pH}$ remained stable at all levels of applied CPAP.

When asked to evaluate their sense of breathlessness, all patients reported either an improvement or no change with CPAP; the scores ranged from 0 to +5 . No individual described a worsening sense of dyspnoea while on CPAP. In reference to the corresponding control period $(\mathrm{CPAP}=0)$, the mean dyspnoea value for CPAP 5 $\mathrm{cmH}_{2} \mathrm{O}$ was $+1.4(\mathrm{p}<0.05)$ improving to $+2.5(\mathrm{p}<0.05)$ and $+2.7(\mathrm{p}<0.05)$ for CPAP 7.5 and $10 \mathrm{cmH}_{2} \mathrm{O}$ respectively.

\section{Discussion}

The major findings of this study are that the non-invasive application of CPAP to spontaneously breathing patients in hypercapnic respiratory failure suffering an acute exacerbation of COPD results in a significant reduction in inspiratory effort and dyspnoea whilst improving the pattern of breathing. Although similar findings have been reported previously in the intubated patient recovering from an episode of respiratory failure; to our knowledge, this has not yet been described in the acutely ill nonintubated COPD patient.

Because of increased flow resistance which results in an abnormally long respiratory time constant, individuals with COPD require a prolonged expiratory phase. Often, because of an inadequate time available for expiration, these individuals fail to reach the resting volume of the respiratory system at end-expiration, i.e. at endexpiration, lung volume is often greater than the relaxed functional residual capacity. This implies that before initiating flow, a certain amount of inspiratory pressure must be developed in order to overcome the positive elastic recoil remaining. Such a threshold load or intrinsic PEEP (PEEPi) has been found to be present in the majority of severe COPD patients, both when stable [7] and in acute respiratory failure $[5,9]$.
In their study of 14 COPD patients in acute respiratory failure, MurCIANO et al. [9] measured an average end-expiratory tracheal occlusion pressure, i.e. static PEEPi of $8.5 \pm 3.5 \mathrm{cmH}_{2} \mathrm{O}$, whilst Petrof et al. [5] documented an average static PEEPi of $9.8 \mathrm{cmH}_{2} \mathrm{O}$ in a cohort of COPD patients recovering from acute respiratory failure and weaning from mechanical ventilation. Although static PEEPi could not be reliably measured in these nonintubated spontaneously breathing patients, there is little reason to expect, given the severe degree of airway obstruction present in the setting of an acute exacerbation and the evidence in the study recordings of significant levels of expiratory flow at the onset of inspiratory effort, that levels of PEEPi substantially different from those reported previously were present in this study. We therefore undertook to determine whether the application of CPAP in its ability to counterbalance the PEEPi present $[1,2]$ on the one hand and unload the inspiratory muscles on the other [10] would reduce inspiratory effort and dyspnoea and improve the pattern of breathing in spontaneously breathing patients with severe obstructive pulmonary disease suffering an acute decompensation.

In addition to the reduction in inspiratory effort the majority of our patients improved subjectively on CPAP, albeit to different degrees. No patient reported a worsening of dyspnoea. These findings may well be due, as suggested by KILLIAN [11], to a decrease in inspiratory effort as demonstrated in the present study. Additionally, it has been suggested that dyspnoea may be heightened by dynamic airway collapse [12]. To the extent that positive pressure applied downstream from the site of flow limitation may decrease dynamic airway compression, this may have further decreased the sense of dyspnoea.

This improvement both in inspiratory effort and breathlessness is very similar to our previous findings reported by PETROF et al. [5], who examined the impact of CPAP on COPD patients during weaning from mechanical ventilation. Although both groups of patients were spontaneously breathing, those studied by PETROF et al. [5] had been intubated for variable periods of time and were no longer acutely ill. This is in contrast to the present study in which all subjects were acutely ill and breathing spontaneously through a native upper airway. 
Arterial blood gases tended to remain the same or improve slightly. The trend toward a reduction in $\mathrm{Pa}_{\mathrm{a}} \mathrm{CO}_{2}$ was probably due to the improvement in breathing pattern [13] given that minute ventilation $\left(V^{\prime} \mathrm{E}\right)$ remained constant. Although we cannot exclude a decrease in $\mathrm{CO}_{2}$ production accruing to the fall in inspiratory effort, any decrease, however modest, would be of benefit.

One major concern relating to the use of extrinsic PEEP in this setting is its effect on lung volume, in that any further hyperinflation would place the inspiratory muscles at greater mechanical disadvantage. Although the ability of RIP to reliably quantify changes in end-expiratory lung volume may be limited [14], the failure of CPAP to alter the end-expiratory positions both of ribcage and abdomen in this present study would suggest that end-expiratory lung volume was not appreciably increased. In addition, end-expiratory $P$ oes fell by a mean of 0.1 $\mathrm{cmH}_{2} \mathrm{O}$ at CPAP $5 \mathrm{cmH}_{2} \mathrm{O}$ whilst it increased by a mean of $1.26 \mathrm{cmH}_{2} \mathrm{O}$ and $1.0 \mathrm{cmH}_{2} \mathrm{O}$ at CPAP 7.5 and 10 $\mathrm{cmH}_{2} \mathrm{O}$, respectively. Assuming a normal chest wall compliance of $200 \mathrm{~mL} \cdot \mathrm{cmH}_{2} \mathrm{O}^{-1}$, this would amount to an average increase in lung volume of approximately $200 \mathrm{~mL}$. This is very similar to those values reported by Petrof et al. [5].

The failure to substantially increase lung volume is consistent with previous investigations in COPD patients $[1,2,15,16]$, in which, in the presence of expiratory flow limitation, end-expiratory lung volume remained constant until the amount of applied PEEP approached the level of PEEPi present. For example, PETROF et al. [5] demonstrated that lung volume remained constant at CPAP of $5 \mathrm{cmH}_{2} \mathrm{O}$ in the absence of expiratory muscle recruitment, whilst at higher levels the degree of hyperinflation was less than would have been predicted by the passive inflation of the respiratory system. Indeed, KIMBALL et al. [17] had shown much the same phenomenon, in that the isovolume pressure-flow curve of a severely obstructed patient was independent of the pressure placed at the airway opening.

Although we believe that the absence of further hyperinflation in our subjects was due to the presence of expiratory flow limitation in the tidal volume range, other possible explanations remain to be considered. Others have reported that in both normals [18, 19] and asthmatics [6] any increase in end-expiratory lung volume accruing to the application of positive-pressure breathing appears to be actively resisted through the recruitment of abdominal expiratory muscles. However, as evidenced by the expiratory gastric pressure tracings, none of the subjects in the present study augmented his/her expiratory muscle recruitment at $5 \mathrm{cmH}_{2} \mathrm{O}$, whilst the majority failed to do so even at $7.5 \mathrm{cmH}_{2} \mathrm{O}$. That is, although these patients actively recruited expiratory muscles at baseline, as has been reported previously [20, $21]$, they failed to increase that recruitment to any appreciable extent even at the higher levels of CPAP.

It should be noted, in this regard, that methodological differences may account for the failure of the patients in this present study to recruit expiratory muscles. Both the patients in the present study and those of PETROF et al. were studied in semirecumbent position, in which expiratory muscle recruitment has been found to occur far less frequently as compared to the seated position in which both MARTIN et al. [6] and Bishop et al. [19] studied their subjects.

Alternatively, this lack of increase in lung volume could be due to CPAP-induced changes in expiratory braking mechanisms, such as glottic narrowing and persistent inspiratory muscle activity during expiration. Whilst we cannot comment on the effect of CPAP on glottic narrowing, inspiratory muscle activity during expiration has been shown not to be increased in individuals with COPD [22] in contrast to subjects with asthma [6].

These findings are in marked contrast to those reported by Tuxen [23] and are most likely due to a fundamental difference in patient population. The latter study documented a progressive increase in lung volume and intrathoracic pressure as increasing levels of extrinsic PEEP were applied to six mechanically-ventilated patients with severe airflow obstruction and hypercapnic respiratory failure. Although detailed patient characteristics are not provided, those patients were not flow-limited during tidal breathing. This may have been due to a lesser degree of airway obstruction or to the presence of asthma, a condition in which flow limitation has generally not been observed [15]. The absence of expiratory flow limitation in severe asthma may be due to the lack of reduced lung recoil and increased airway collapsibility that characterize COPD [16].

It is becoming increasingly clear that the therapeutic approach to the severely ill COPD patient with an acute exacerbation should not be limited to conventional pharmacological treatment. In this regard, BROCHARD et al. [24] have recently reported their experience in treating such patients with noninvasive inspiratory assistance by means of a face-mask. They found that, in comparison with a historical control group, the noninvasively ventilated subjects required intubation and conventional mechanical ventilation significantly less often. In addition, the period of time requiring ventilatory assistance and the number of ICU days were significantly shortened. We cannot, at this time, comment on whether CPAP or noninvasive mechanical ventilation is superior or whether certain clinical conditions favour the use of one versus the other. It is likely, however, that both forms of ventilatory support can complement one another in providing optimal reduction in inspiratory effort.

In summary, we have found that the application of CPAP to spontaneously breathing patients suffering an acute exacerbation of COPD decreases inspiratory effort and dyspnoea while improving the pattern of breathing. Whilst it was not the purpose of this study to evaluate whether or not the application of CPAP in this setting could obviate the need for mechanical ventilation, such potential clearly exists and warrants further study.

Acknowledgements: The authors would like to thank C. Segura and the ICU nursing staff of the Montreal Chest Hospital Centre for their enthusiastic co-operation in this study. They also thank J. Milic-Emili for his contributions to this manuscript and J. Longo for her secretarial assistance. 
Supported in part by the Medical Research Council of Canada, the Canadian Cystic Fibrosis Foundation, the J.T. Campbell Memorial Research Fund, and the Montreal Chest Hospital Centre Research Institute. S.G. was a Medical Research Scholar of the Fonds de la Recherche en Santé du Québec. F.M. was a Recipient of Fellowship Awards from the Canadian Lung Association and the Fonds de la Recherche en Santé du Québec.

\section{References}

1. Simkovitz P, Brown K, Goldberg P, Milic-Emili J, Gottfried $\mathrm{S}$. Interaction between intrinsic and externally applied PEEP during mechanical ventilation. Am Rev Respir Dis 1987; 135: 202.

2. Smith TC, Marini JJ. Impact of PEEP on lung mechanics and work of breathing in severe airflow obstruction. J Appl Physiol: Respirat Environ Exercise Physiol 1988; 65: 1488.

3. Marini JJ, Rodriguez RM, Lamb V. The inspiratory workload of patient-initiated mechanical ventilation. Am Rev Respir Dis 1986; 134: 902-909.

4. Baydur A, Behrakis PK, Zib WA, Jaeger M, Milic-Emili J. A simple method for assessing the validity of the esophageal balloon technique. Am Rev Respir Dis 1982; 126: 788-791.

5. Petrof BJ, Legare M, Goldberg P, Milic-Emili J, Gottfried $\mathrm{SB}$. Continuous positive airway pressure reduces work of breathing and dyspnea during weaning from mechanical ventilation in severe chronic obstructive pulmonary disease. Am Rev Respir Dis 1990; 141: 281-289.

6. Martin JG, Shore S, Engel LA. Effect of continuous positive airway pressure on respiratory mechanics and pattern of breathing in induced asthma. Am Rev Respir Dis 1982; 126: 812-817.

7. Haluszka J, Chartran DA, Grassino AE, Milic-Emili J. Intrinsic PEEP and arterial $\mathrm{PCO}_{2}$ in stable patients with chronic obstructive pulmonary disease. Am Rev Respir Dis 1990; 141: 1194-1197.

8. Beutler E, Schneider KE, Frincke LA. Reference Manager Retrieval System. N Engl J Med 1991; 302: 26-32.

9. Murciano D, Aubier M, Bussi S, Derenne JP, Pariente R, Milic-Emili J. Comparison of esophageal, tracheal and mouth occlusion pressure in patients with chronic obstructive pulmonary disease during acute respiratory failure. Am Rev Respir Dis 1982; 126: 837-841.

10. O'Donnell DE, Sanii R, Giesbrecht G, Younes M. Effect of continuous positive airway pressure on respiratory sensation in COPD. Am Rev Respir Dis 1988; 138:11851191.

11. Killian KJ, Campbell EJM. Dyspnea. In: Lenfant C, ed. The Thorax. New York, Marcel Dekker, 1985.
12. O'Donnell DE, Sanii R, Anthonisen NR, Younes M. Effect of dynamic airway compression on breathing pattern and respiratory sensation in severe chronic obstructive pulmonary disease. Am Rev Respir Dis 1987; 135: 912-918.

13. Roussos Ch. Ventilatory failure and respiratory muscle. In: Lenfant C, ed. The Thorax. New York, Marcel Dekker, 1985.

14. Werchowski JL, Sanders MH, Constantino JP, Sciurba FC, Rogers RM. Inductance plethysmograph measurement of CPAP-induced changes in end-expiratory lung volume. J Appl Physiol: Respirat Environ Exercise Physiol 1990; 68: 1732-1738.

15. Marini JJ. Should PEEP be used in airflow obstruction? Am Rev Respir Dis 1989; 140: 1.

16. Gottfried SB. The role of PEEP in the mechanicallyventilated COPD patient. In: Marini JJ, Roussos Ch. ed. Ventilatory Failure. Berlin, Springer-Verlag, 1991; pp. 392-418.

17. Kimball WR, Leith DE, Robins AR. Dynamic hyperinflation and ventilator dependence in chronic obstructive pulmonary disease. Am Rev Respir Dis 1982; 126: 991-995.

18. Urbscheit N, Bishop B, Bachofen H. Immediate effects of continuous positive pressure breathing on abdominal expiratory activity, minute ventilation and end-tidal $\mathrm{PCO}_{2}$ of conscious man. Phys Ther 1973; 53: 258.

19. Bishop B, Hirsch J, Thursby M. Volume flow and timing of each breath during positive-pressure breathing in man. J Appl Physiol: Respirat Environ Exercise Physiol 1978; 45: 495-501.

20. Martinez FJ, Couser JI, Celli BR. Factors influencing ventilatory muscle recruitment in patients with chronic airflow obstruction. Am Rev Respir Dis 1990; 142: 276-282.

21. Ninae V, Rypens F, Yernault JC, De Troyer A. Abdominal muscle use during breathing in patients with chronic airflow obstruction. Am Rev Respir Dis 1992; 146: 16-21.

22. Citterio G, Agostoni E, Del Santo A, Marazzini L. Decay of inspiratory muscle activity in chronic airway obstruction. J Appl Physiol: Respirat Environ Exercise Physiol 1981; 45: 1388-1397.

23. Tuxen DV. Detrimental effects of positive end-expiratory pressure during controlled mechanical ventilation of patients with severe airflow obstruction. Am Rev Respir Dis 1989; 140: 5-9.

24. Brochard L, Isabey D, Piquet J, et al. Reversal of acute exacerbations of chronic obstructive lung disease by inspiratory assistance with a face-mask. N Engl J Med 1990; 323: $1523-1530$.

25. Roussos Ch. Energetics. In: Roussos Ch, Macklem PT, eds. The Thorax. New York, Dekker, 1985; p. 469. 